\title{
Hermenêutica de Profundidade: um referencial, dois ensaios e alguns apontamentos
}

\section{Hermeneutics of Depth: a reference, two essays and some notes}

\author{
Mirian Maria Andrade ${ }^{1}$ \\ Fernando Paulino de Cerqueira Netto ${ }^{2}$
}

\begin{abstract}
Resumo
Neste artigo apresentam-se duas análises de formas simbólicas distintas, disparadas por meio do Referencial Metodológico da Hermenêutica de Profundidade (HP). Os dois textos analisados são antigos, impressos, e de autoria de Silvestre F. Lacroix, ambos traduzidos para a língua portuguesa: Ensaios sobre o Ensino em Geral e o de Matemática em Particular (1838); Introdução ao conhecimento da esfera (1872). A partir dessas duas análises, a intenção é apresentar alguns apontamentos que esses estudos permitem tecer sobre a análise de textos escritos quando a HP é mobilizada, sobretudo em História da Educação Matemática.
\end{abstract}

Palavras-chave: Hermenêutica de Profundidade; Lacroix; Interpretação de textos.

\begin{abstract}
This article presents two analyzes of distinct symbolic forms, triggered by the Methodological Referential of Depth Hermeneutics (HP). The two texts analyzed are old, printed, and authored by Silvestre F. Lacroix, both translated into Portuguese: Essays on Teaching in General and Mathematics in Particular (1838); Introduction to the knowledge of the sphere (1872). From these two analyzes, the intention is to present some notes that these studies allow to weave on the analysis of written texts when HP is mobilized, especially in History of Mathematical Education.
\end{abstract}

Keywords: Hermeneutics of Depth; Lacroix; Interpretation of texts.

\section{Introdução}

Há alguns anos temo-nos debruçado, sobretudo em História da Educação Matemática, a pensar em exercícios hermenêuticos de análise por meio do Referencial Metodológico da Hermenêutica de Profundidade (HP). Algumas pesquisas têm se dedicado especificamente ao estudo deste referencial quando o mobilizam para elaborar interpretações de textos escritos. Neste artigo, em particular, nossa intenção é apresentar duas análises de textos (dois livros,

\footnotetext{
Submetido em: 30/11/2018 - Aceito em: 26/04/2019 - Publicado em: 26/04/2019

${ }^{1}$ Doutora em Educação Matemática pela Universidade Estadual Paulista Julio de Mesquita Filho (Unesp), campus Rio Claro. Professora da Universidade Tecnológica Federal do Paraná (UTFPR), campus Curitiba. Brasil. Email: andrade.mirian@gmail.com ${ }^{2}$ Mestrando do Programa de Pós-Graduação. Mestrado Profissional em Ensino de Matemática, UTFPR/campus
Londrina e Cornélio Procópio. Email: fer_netto123@hotmail.com
} 
DOI: http://dx.doi.org/10.20396/zet.v27i0.8654109

especificamente) realizadas neste cenário e, então, disparar apontamentos sobre a HP como metodologia a partir desses dois exames hermenêuticos.

A HP como metodologia é proposta por Thompson (1995), que toma como fundamento, para conceber "texto", as compreensões de Ricoeur ${ }^{3}$. De acordo com Oliveira (2008, p. 31), para Ricoeur:

o ser humano vive em um mundo formado por símbolos por ele criados por meio da interpretação. Símbolo, para ele, é tudo o que se abre à interpretação e não se dá prontamente, tendo, portanto, um significado "latente" e um "interpretado". É através dos símbolos que o Homem se aproxima e interage com o "real". Para compreender a existência humana, então, Ricoeur acredita ser necessário um esforço hermenêutico sobre os símbolos que, sistematicamente estruturados, compõem "textos". Nesse sentido é que podemos dizer que, para Ricoeur, "tudo é texto" [ênfases no original].

Oliveira (2008), então, defende a mobilização da HP, baseado em Thompson, que tem Ricoeur como seu interlocutor, tomando "texto" de acordo com este seu principal interlocutor. Assim, também a concepção de texto que temos apontado nos trabalhos que desenvolvemos baseia-se em Ricoeur.

É nesse sentido que a HP surge, basicamente, como uma teoria da interpretação de textos, tomando o termo "texto" em sentido amplo (um conjunto de símbolos que são criações humanas carregadas de intenções cujo significado é atribuído por aquele que o lê, num processo hermenêutico, interpretativo). A HP revela-se, então, como uma possibilidade de análise de formas simbólicas ${ }^{4}$, numa abordagem que vincula, ao mesmo tempo, elementos historiográficos e sociológicos, e está filosoficamente enraizada na Fenomenologia Hermenêutica de Paul Ricoeur. É por essa lente que Ricoeur (e vários filósofos seus contemporâneos) considera um texto como uma produção humana intencional (ou que possa ser assumida como tal), materializada em símbolos e, portanto, aberta à interpretação. Ressaltamos que Thompson não sugere a HP como possibilidade metodológica pensando formas simbólicas somente como sendo textos escritos. Mas neste trabalho, em específico, tomaremos texto como texto escrito.

As duas análises que pretendemos chamar à cena foram construídas a partir da nossa tentativa de interpretação de dois livros antigos impressos, ambos de autoria de Silvestre F. Lacroix e traduzidos para a língua portuguesa: Ensaios sobre o Ensino em Geral e o de Matemática em Particular (1838) ${ }^{5}$; Introdução ao conhecimento da esfera (1872). Mobilizamos, portanto, a HP com a finalidade de disparar interpretações de dois textos de Lacroix ${ }^{6}$. A tradução dessas duas obras por Karina Rodrigues, em parceria com o $\mathrm{Ghoem}^{7}$, se

\footnotetext{
${ }^{3}$ Paul Ricoeur (1913-2005), filósofo e pensador francês.

${ }^{4}$ Mais à frente, neste texto, trataremos de esclarecer com mais cuidado o que são formas simbólicas. Por ora, o leitor pode entendê-las como criações humanas intencionais.

${ }^{5} \mathrm{O}$ trabalho completo que inclui a análise aqui mencionada pode ser consultado em Andrade (2012).

${ }^{6}$ Sylvestre-François Lacroix (1765-1843), nascido em Paris, foi um matemático, educador e autor de diversos livros didáticos de grande sucesso. Foi um dos mais influentes autores de livros didáticos de matemática. Viveu Zetetiké, Campinas, SP, v.27, 2019, p.1-15 - e019015

ISSN 2176-1744
} 
DOI: http://dx.doi.org/10.20396/zet.v27i0.8654109

deu em momentos distintos, mas com objetivos similares: interpretar Lacroix. A tradução do Ensaios ... ${ }^{8}$ foi realizada por uma necessidade recorrente para o desenvolvimento da pesquisa de doutoramento de Andrade (2012), e a tradução do Introdução ao conhecimento da Esfera foi publicada junto com uma coletânea de textos que apresentam algumas pesquisas que mobilizaram a HP em seus exercícios analíticos ${ }^{9}$, e só alguns anos depois é que ela foi tomada como objeto de análise em nossas pesquisas.

Ensaios sobre o Ensino em Geral e o de Matemática em Particular é uma obra mais ampla, em que o autor se propõe a falar sobre o ensino de matemática e apresenta uma autoanálise de suas obras didáticas, e que consideramos ser de natureza diferenciada das demais obras deste autor: de caráter autobiográfico, escrita por um autor reconhecido por sua produção de livros didáticos de matemática. O livreto Introdução ao conhecimento da Esfera é um texto menor, o que poderíamos chamar, na contemporaneidade, de um livro de bolso. Podemos considerar que é outra obra de Lacroix com características peculiares, quando comparada a grande parte de sua produção: um livreto, pequeno em formato e em número de laudas, cujo assunto principal não se configura como um conteúdo específico de matemática, apesar de chamar à cena vários conteúdos de matemática para permitir ao leitor a compreensão daquilo que se dispõe a tratar.

A HP nos permitiu compor uma interpretação para cada uma dessas duas obras peculiares deste autor francês, com características muito próprias, singulares. No que segue, apresentaremos o referencial e o modo como ele foi mobilizado para a análise desses dois textos, as respectivas análises que nos foram possíveis quando a HP foi por nós utilizada, bem como nossas considerações sobre este referencial teórico metodológico.

\section{O Referencial Metodológico da Hermenêutica de Profundidade (HP)}

O Referencial Metodológico da Hermenêutica de Profundidade é proposto por Thompson (1995), em sua obra Ideologia e cultura moderna: teoria social crítica na era dos meios de comunicação de massa. Ele sinaliza essa possibilidade metodológica com a intenção de analisar a ideologia das formas simbólicas e, ao sinalizar essa sugestão metodológica para tal intenção, preocupa-se em esclarecer ao seu leitor, possível hermeneuta, sobre o conceito de ideologia ${ }^{10}$, sobre a forma como a ideologia impera nas sociedades modernas e revela, assim, o que entende por cultura ${ }^{11}$. Coloca-se, então, a discorrer sobre a

\footnotetext{
num período revolucionário, com muitas mudanças nas estruturas sociais e políticas e também na educação. Tornou-se, no século XIX, o autor francês mais frequentemente traduzido para outros idiomas (Andrade, 2012)

${ }^{7}$ Grupo História Oral e Educação Matemática.

${ }^{8}$ A tradução foi publicada (Lacroix, 2013) após a conclusão do doutoramento de Andrade (2012) e foi a versão usada por esta autora para disparar sua análise hermenêutica.

${ }^{9}$ O livreto original, em francês, compõe o acervo do Ghoem, nas dependências físicas da Unesp-Bauru/SP. A tradução está publicada em Garnica e Salandim (2014).

${ }^{10}$ Thompson entende ideologia, nesta obra, como "sentido a serviço do poder".

11 Thompson dedica um capítulo do seu livro para discutir o conceito de cultura. Para isso ele toma como base os trabalhos de antropólogos, como Geertz. Grosso modo, é possível afirmar que o conceito de cultura adotado por Thompson $(1995$, p. 22) pode ser "adequadamente usado para se referir, de uma maneira geral, ao caráter Zetetiké, Campinas, SP, v.27, 2019, p.1-15 - e019015

ISSN 2176-1744
} 
DOI: http://dx.doi.org/10.20396/zet.v27i0.8654109

transmissão cultural e a comunicação de massa. Sugere, nesta obra, um referencial crítico para análise dos fatos comunicacionais, que abrange desde o contexto sócio-histórico em que se dão os fatos, até os processos de produção, transmissão e recepção das formas simbólicas ${ }^{12}$. Para Thompson (1995, p. 16), “o estudo da ideologia... exige que investiguemos os contextos sociais dentro dos quais essas formas simbólicas são empregadas e articuladas”.

Segundo este autor, a mobilização da HP se dá quando o objeto de análise pode ser compreendido, então, como uma forma simbólica. Ele ressalta, ainda, que uma forma simbólica apresenta alguns aspectos (intencional, contextual, estrutural, convencional e referencial) para que assim possa ser considerada, e tais aspectos devem ser ponderados pelo hermeneuta que se propõe a lançar mão da HP em sua investigação.

O aspecto intencional vincula-se a uma intenção: formas simbólicas são produzidas com a intencionalidade de alguém e, portanto, manifestam o querer dizer algo (intenção de quem as produz), e o hermeneuta intenciona compreender o que se pretendeu dizer. Além de manifestar uma intenção, toda forma simbólica é produzida, apresentada ao público e mobilizada dentro de um (ou alguns) contexto(s) histórico(s), social(ais) e cultural(ais), conectada a uma época, a um "mundo" e a indivíduos específicos que compõem esse mundo e essa época, revelando que toda forma simbólica possui um aspecto contextual. ${ }^{13} \mathrm{E}$ as intenções da forma simbólica podem estar sensíveis às influências desses contextos, sobretudo, em momentos de produção. Entretanto, outros contextos podem também expor o hermeneuta e a forma simbólica a essa sensibilidade, em momentos de interpretação. Essas formas simbólicas respondem, também, a algumas convenções, a alguns códigos e a algumas regras (tentativas de comunicação nem sempre explícitas), quando de sua produção e de sua circulação, determinando o que Thompson denomina de "aspecto convencional". A intenção de dizer algo, num determinado contexto, gera essa necessidade. Assim como dispara a necessidade de se mostrar com uma estrutura determinada por elementos internos que se articulam e se organizam entre si para constituir a forma simbólica, o que tem sido compreendido como o aspecto estrutural das formas simbólicas. Por fim, outra característica das formas simbólicas é que elas falam de alguma coisa (intenção) e sobre ela (aspecto referencial), e a intenção do autor está sempre acompanhada do objeto de sua manifestação, que, por sua vez, é o objeto do discurso, o referencial da forma simbólica.

Ao assumirmos formas simbólicas de acordo com essas disposições de Thompson, podemos afirmar que um livro (seja ele didático ou não) pode ser tomado como uma forma simbólica. Algumas pesquisas, como a de Andrade (2012), por exemplo, analisam detalhadamente esses aspectos para verificar se podem, a partir deles, tomar livros como

simbólico da vida social, aos padrões de significado incorporado às formas simbólicas compartilhadas na interação social".

${ }^{12}$ Formas simbólicas são construções humanas intencionais, são ideológicas e envolvem um produtor e um receptor. Thompson considera que "as formas simbólicas são ideológicas quando servem para estabelecer ou sustentar relações de dominação, ou seja, quando as formas simbólicas contribuem para a manutenção sistematicamente assimétrica das relações de poder" (Andrade \& Oliveira, 2014, p. 23). 
DOI: http://dx.doi.org/10.20396/zet.v27i0.8654109

formas simbólicas: "um livro é uma produção humana carregada de intenções, possui uma estrutura específica, responde a várias e determinadas convenções e refere-se ao seu objeto de forma contextualizada" (Andrade, 2012, p. 30). São esses exercícios anteriores de pesquisa que nos permitem - sem que sejam necessários novos e repetitivos detalhamentos - esta afirmativa: livros podem ser considerados formas simbólicas e, portanto, são passíveis de interpretação por meio da HP.

Essa proposta teórico-metodológica de Thompson (1995) se apresenta sob a forma de três fases ou dimensões, denominadas de análise sócio-histórica, análise formal ou discursiva e interpretação/reinterpretação. A análise sócio-histórica consiste em analisar a forma simbólica sob o olhar do contexto sócio-histórico e cultural em que ela foi produzida e circulou. Permite compreensões vindas de um olhar externo ao objeto. É, portanto, um olhar para além do objeto em si, mas o que dispara este olhar é o próprio objeto ${ }^{14}$. A análise formal $^{15}$ ou discursiva, no entanto, sugere um debruçar sobre a forma simbólica em si, um longo debruçar sobre ela mesma. Esse olhar para o contexto é essencial para traçarmos uma compreensão do objeto em si, sem que essa seja uma análise meramente descritiva, e nos ajuda a revelar diversos aspectos do objeto em análise. O movimento dessas instâncias analíticas, segundo Thompson, acontece de forma concomitante, e é ele que permite ao hermeneuta lançar uma interpretação da forma simbólica, que se reinterpreta a todo instante e se constitui, em trajetória, durante a análise sócio-histórica e a análise formal ou discursiva. Oliveira (2014) nos alerta que o ponto alto da teorização de Thompson está na correlação, ressaltada sob o nome de (re)interpretação.

\section{Mobilizações da HP: leituras e interpretações de Lacroix}

- Uma análise: o caso da obra Ensaios sobre o Ensino em Geral e o de Matemática em Particular $^{16}$

A estrutura diferenciada da obra nos chamou a atenção por não se tratar de um livro voltado para a apresentação de um conteúdo específico de matemática para ser usado em sala de aula - não é um livro didático no mesmo sentido dos vários livros didáticos do mesmo Lacroix. Trata-se de um livro que investiga, questiona e pretende ser um registro historiográfico sobre o ensino de matemática; tem Lacroix como o autor; e refere-se à

14 Para a análise sócio-histórica, Thompson sugere cinco tipos diferentes de análises que podem ser desenvolvidas pelo hermeneuta e esclarece, ainda, que são apenas sugestões e outras sugestões podem surgir. São elas: análise das instituições sociais, dos campos de interação, das situações espaçotemporais, da estrutura social e dos meios de transmissão e comunicação.

15 Analogamente, Thompson sugere, para a análise formal, outros cinco modos que, pensa, podem bem funcionar para disparar as análises de formas simbólicas quando se propõe um olhar mais interno ao objeto: análise argumentativa, análise narrativa, análise sintática, análise de conversação e análise semiótica.

${ }^{16}$ Textos que tratam desta análise já foram publicados em outros momentos e constam, também, como parte das referências deste trabalho. No entanto, consideramos relevante chamá-la à cena, junto à análise da outra obra, visto que são esses dois exames hermenêuticos que nos permitem traçar os apontamentos que aqui nos propusemos. Portanto, nos pareceu necessário tratar das duas análises, mesmo que brevemente, para que pudéssemos tratar das considerações que elas nos possibilitaram.

Zetetiké, Campinas, SP, v.27, 2019, p.1-15 - e019015

ISSN 2176-1744 
DOI: http://dx.doi.org/10.20396/zet.v27i0.8654109

Educação (em geral) e ao ensino de matemática. É uma coletânea de reflexões, que o próprio autor assume serem de caráter historiográfico, sobre o ensino na França, seguidas de uma descrição analítica de sua obra didática - os livros do Cours de Mathématiques -, uma série de livros para o ensino, publicados nos anos de 1797 a 1802, composta por títulos relativos à Aritmética, à Álgebra, à Geometria, à Trigonometria e ao Cálculo Diferencial e Integral.

$\mathrm{Na}$ análise sócio-histórica estudamos o contexto em que a forma simbólica foi pensada, produzida e, posteriormente, circulou. Tentamos "compreender o pensamento" de Lacroix e as possíveis influências desse contexto na escrita de sua obra. Buscamos ao mesmo tempo estranhá-lo (visto que o estranhamento autêntico é essencial num processo de suspeição) e evitar um possível estranhamento - que ocorreria, se considerássemos seu discurso como despregado das situações contextuais em que viveu. Foi preciso, portanto, analisar seu discurso dentro dos parâmetros contextuais, sociais, econômicos e políticos dos séculos XVIII e XIX, sobretudo na França.

A primeira edição desta obra é de 1805 . O exemplar que consta no acervo do Ghoem (e que tomamos como objeto central da nossa pesquisa) é uma quarta edição (1838). Verificamos que o texto apresenta uma defesa apaixonada do Iluminismo ${ }^{17}$ e que suas edições conseguem atravessar o momento revolucionário, o período napoleônico ${ }^{18}$ e alcançar a Restauração, com o retorno da Monarquia. Isso nos levou a questionar como Lacroix se relacionava no meio em que vivia, num período de grandes mudanças políticas e sociais, a ponto de continuar publicando este texto, praticamente sem alterações, defendendo um ideal já rejeitado. Essa análise nos permitiu compreender que Lacroix era moderado, com opiniões progressistas, bem ao gosto da tradição iluminista do século XVIII, sem pertencer ao grupo político dos jacobinos que lhe garantiu posições oficiais no programa de reformas das instituições educacionais francesas. Permitiu-nos, também, conhecer a produção de Lacroix, seu momento de maior produção (que foi justamente a época em que esta obra teve sua primeira edição publicada) e o momento de declínio de sua produção (que compreende o período de publicação das demais edições desta obra).

A análise da obra em si, por sua vez, deu-se mais propriamente com a análise formal, quando, além de nos debruçarmos sobre os elementos que compõem a narrativa e sobre a própria narrativa como um todo coeso, atentamos também para os demais elementos que, de

\footnotetext{
${ }^{17}$ Movimento que teve início no século XVII e alcançou seu auge no século XVIII. O termo "iluminismo" vem de "luzes", posto que era um esforço para tirar os homens do domínio da superstição e da ignorância, iluminando as trevas na qual a sociedade esteve imersa por longo tempo.

${ }^{18}$ Em 1804, Napoleão proclamou-se Imperador com as bênçãos do Papa Pio VII e, dessa forma, teve início o Império Napoleônico, que se estendeu até 1814. Sob o poder de Napoleão, a imprensa foi censurada e, no que se refere à educação, foram alterados os programas das disciplinas de História e Filosofia, disciplinas perigosas demais para o seu regime de governo. Desse modo, a população aprendia tanto os deveres para com Deus quanto os deveres para com o Imperador. Napoleão restabeleceu a escravidão nas colônias, e tomou outras atitudes que promoviam o abandono do ideário revolucionário. Em 1813, Napoleão perdeu uma disputa contra a aliança constituída pela Prússia, Rússia e Áustria. Em seguida, foi preso, mas fugiu em março de 1815 e voltou à França, onde assumiu novamente o poder (no período denominado "Governo dos cem dias"). No entanto, foi finalmente detido por uma coligação europeia que restituiu o poder a Luis XVIII. Com isso, teve início o período da História da França denominado Restauração (1814-1848), quando se consolidou a rejeição às teorias iluministas (consideradas culpadas pela desordem provocada pela Revolução).
}

Zetetiké, Campinas, SP, v.27, 2019, p.1-15 - e019015

ISSN 2176-1744 
DOI: http://dx.doi.org/10.20396/zet.v27i0.8654109

certo modo, constituem a obra, com foco principalmente nos elementos "internos" do livro, como sua materialidade (a capa, o material e as informações das páginas internas, o nome do autor, o formato da obra, o título, o sumário, a [ausência de] dedicatória e epígrafes, as notas presentes no texto, o prefácio e a sequenciação do texto). Neste momento analítico, nos pautamos principalmente na concepção de paratextos ${ }^{19}$ apresentada por Genette (2009). Trabalhamos, também, com fragmentos do texto, num movimento de recortar, de registrar para posteriormente apreciá-los e fazê-los dialogar, para produzirmos um discurso sobre a obra, ao que chamamos de análise argumentativa. A primeira parte desse livro trata mais geralmente da Reforma da Instrução Pública francesa implantada segundo o ideário da Revolução; e a segunda parte refere-se ao ensino de Matemática. Nela, enfaticamente, Lacroix apresenta e discute, de modo detalhado, os livros compostos para as Escolas Centrais - os manuais do Cours de Mathématiques. Ao tratar dessa sua coleção, Lacroix considera suas intenções de autor e as particularidades de cada um dos livros, tanto do ponto de vista da organização e da exposição dos conteúdos quanto do ponto de vista didático e pedagógico. Para a análise dessa segunda parte, portanto, julgamos necessário cotejar essas disposições do autor com cada um dos livros da coleção, disparando, por exemplo, o estudo (e a tradução) de todos os sumários dos livros que compõem o Cours.

A análise sócio-histórica e a formal nos possibilitaram elaborar uma hermenêutica dessa obra no registro da interpretação/reinterpretação e considerar esta obra como um escrito muito minucioso, no qual o autor faz sobressair, por diversas vezes, suas próprias experiências como docente. É um depoimento, um escrito testemunhal de um estado de coisas do qual um autor específico, nomeado claramente e participante ativo nas tramas que ajudaram a constituir um sistema nacional de instrução para a França do final do Setecentos, pode dar conta.

Esse livro - pensado, escrito e publicado por um professor de matemática atento a suas experiências em sala de aula e também reconhecido autor de livros didáticos de matemática, cuja obra é considerada a mais traduzida para outros idiomas, inclusive o português (o que nos revela o grande alcance dos livros didáticos de Lacroix no ensino de Matemática) - é considerado pelo próprio autor como complemento de suas outras obras publicadas. Podemos afirmar que um dos seus principais temas é a defesa apaixonada dos ideais das Luzes e do modelo de instrução revolucionário, pautado naquele ideário.

\footnotetext{
${ }^{19}$ Paratextos editoriais, de acordo com Genette, é tudo aquilo que faz um texto se tornar livro, como o nome do autor, o título da obra, o prefácio, as notas de rodapé, as dedicatórias etc. Essa concepção de Genette se faz a partir do modo como o autor considera texto. Para ele, texto é o "miolo" do livro, e tudo ao seu redor pode ser considerado paratexto. Nesta nossa pesquisa, mesmo tomando texto num sentido mais amplo que o tomado por Genette, os paratextos editoriais funcionaram muito bem como um apoio na nossa HP, já que nossa forma simbólica era um livro, e Genette trata dos paratextos editorias especificamente para análise de livros.
} 
- Outra análise: o caso do livreto Introdução ao conhecimento da esfera ${ }^{20}$

A primeira edição do livreto Introdução ao conhecimento da esfera foi publicada em 1828. É um livro de formato pequeno, $15 \times 9 \mathrm{~cm}$, escrito originalmente em francês. Mobilizando a HP, traçamos uma análise formal do livreto, olhando mais propriamente para a estrutura interna do material, e uma análise sócio-histórica, cuja intenção foi compreender essa estrutura também pelo contexto sociocultural e político em que ele foi produzido e circulou.

Chamou-nos a atenção o título Introdução ao Conhecimento da Esfera, que impulsionou a indagação: “que esfera?”. Inicialmente pensávamos em um texto matemático e esperávamos por ele - cujo objeto de referência para o autor era a esfera da Geometria Espacial, já que Lacroix se destacou, na França revolucionária, por escrever livros didáticos de Matemática. No folhear das páginas, não encontramos um texto matemático, encontramos um texto que lança mão de muitos elementos da matemática, mas para tratar, sobretudo, de astronomia. A esfera para a qual Lacroix chama a atenção, a ponto de usá-la como elemento central no próprio título da obra, é a esfera armilar, uma máquina que simula o movimento dos astros, tendo o planeta Terra como referência.

Um livreto: poucas páginas, pequeno em extensão e em formato, quando comparado às outras obras deste mesmo autor. Essa sua escolha, ou da editora (não nos é possível precisar), pode estar relacionada às ambições relativas ao material: não ser um livro didático, propriamente dito, embora pareça haver a pretensão de que seja um material de apoio pedagógico. A primeira edição do livreto foi publicada no período de declínio das publicações de Lacroix, num momento em que ele já não publicava mais obras inéditas, apenas novas edições de suas obras antigas e, essas, sem modificações significativas.

Dividida em quatro seções, uma característica dessa obra é que grande parte dela é apresentada como uma sequência de perguntas (indicadas por um "Q:" precedente) e respostas (indicadas por um "R:" precedente) - ambas feitas pelo próprio autor, um estilo bastante usual nos livros antigos. A obra de D. João de Castro, Tratado da Esfera por Perguntas e Respostas, de 1535, por exemplo, também seguia esse mesmo formato de Lacroix, embora seja cerca de trezentos anos mais antiga. Diferentemente de Lacroix, a obra de D. João de Castro é um diálogo entre discípulo e mestre, em que o discípulo faz perguntas que são respondidas por seu mestre. Lacroix, possivelmente, recorreu ao formato de perguntas e respostas como uma forma mais prática e objetiva de desenvolver o livreto, um modo, talvez, sucinto, de tratar sobre o assunto desejado no pouco espaço que as poucas

${ }^{20}$ Auxiliaram-nos também, nesta análise, alguns trabalhos, cedidos a nós pelo professor Antônio Vicente Marafioti Garnica (a quem agradecemos), que foram desenvolvidos em uma disciplina de pós-graduação em que os alunos, após a leitura da tradução do livreto, descreveram possibilidades para uma análise hermenêutica do livreto de Lacroix. Essa atividade foi desenvolvida na disciplina de História da Educação Matemática, ministrada pelos professores Antônio Vicente Marafioti Garnica, Maria Ednéia Martins Salandim e Ivete Maria Baraldi, no Programa de Pós-Graduação em Educação para a Ciência, da Faculdade de Ciências da Unesp/Bauru - SP, em 2016. O exercício desses alunos, registrado nesses trabalhos, nos permitiu pensar caminhos possíveis para a análise do livreto. E essas possibilidades também fazem parte do caminho escolhido. 
DOI: http://dx.doi.org/10.20396/zet.v27i0.8654109

páginas pequenas do livreto ofereciam. Foi publicado pela editora Gauthier-Villars ${ }^{21}$, indicação grafada também na primeira página da tradução, junto ao endereço da editora (rua Quaid es Grands-Augustins, 55, em Paris, na França), o que corrobora a afirmação de Andrade (2012, p. 161): "Lacroix sempre teve sua obra publicada por editoras cuja opção central era a divulgação científica, como as casas Courcier, Mme. Ve. Courcier, Bachelier e Gauthier-Villars".

A nota inicial, dirigida ao leitor, é um pequeno texto de quatro parágrafos, em que Lacroix se propõe a falar sobre o ensino de astronomia. Também no Ensaios..., o autor apresenta uma nota inicial com a qual comunica ao leitor o objetivo que o leva à escrita e à publicação de tal material. É ali clara a crítica que o autor estabelece à metodologia de ensino que utiliza somente a esfera armilar como fonte de observação do movimento dos astros. É nesta nota, também, que Lacroix se refere ao livro Tratado Elementar de Geografia, que, para ele, limita-se a descrever a esfera como uma invenção capaz de fornecer uma ideia sobre os movimentos aparentes dos astros.

$\mathrm{Na}$ apresentação deste pequeno texto, muita coisa sobre a intenção do autor fica explícita. Lacroix, como um professor que atuou em vários níveis de ensino e teve cargos importantes na educação francesa, mostra-se insatisfeito com o ensino nas escolas. Segundo ele, a esfera armilar, apesar de promover uma noção intuitiva, não se compara com a realidade do céu, pois nele não há círculos de aço, madeira ou papelão que orientam os astros, nem eixo de ferro que suporte todo o movimento, e o dinamismo do céu é mais sofisticado, harmônico e variante do que o mecanismo da esfera armilar. Por outro lado, os livros de geografia da época, segundo Lacroix, parecem não fazer nada mais do que encher a cabeça das crianças com palavras incompreensíveis, pois lançam mão de uma linguagem muito teórica e objetiva e acabam por atrapalhar, ao invés de favorecer, o aprendizado: reduzem a esfera armilar a uma invenção capaz de fornecer uma ideia sobre o movimento dos astros, sem apontar suas utilizações. É nesse sentido que Lacroix alega que a observação do céu horas antes do amanhecer e horas depois do anoitecer seria mais eficaz para tratar de noções precisas sobre o movimento dos astros.

Num segundo momento, Lacroix cuida de apresentar a definição de linha, de plano e de linha curva, de forma semelhante ao que vemos atualmente nos livros de geometria euclidiana; e segue apresentando outros elementos matemáticos que julga necessários para a compreensão do que deseja expor nas perguntas e respostas que aparecerão a partir da terceira parte do livreto. As imagens às quais o autor recorre para ilustrar esses termos não estão no corpo do texto, são referenciadas em um anexo que contém onze figuras, numa mesma página (a última do livreto), e que são chamadas à cena por Lacroix, para observação, no decorrer do texto. Todas elas são citadas nesta parte do livreto, o que nos remete à ideia de

21 A Gauthier-Villars publicou obras de grandes nomes da matemática, como Cauchy, Fermat, Fourier, Lagrange e Lacroix. Caracterizava-se, sobretudo, por ser uma editora-impressora e livraria, o que era algo bastante incomum na época. 
DOI: http://dx.doi.org/10.20396/zet.v27i0.8654109

que a primeira seção é dedicada aos leitores que tenham pouco conhecimento na área de geometria, pois são figuras que exemplificam visualmente o que é linha reta, linha curva, linhas perpendiculares, linhas paralelas, ângulos, circunferência, semicírculo e esfera. Conhecer a noção desses termos pode facilitar no entendimento da sequência de seu texto. Para isso, o autor faz uso de uma escrita breve e objetiva.

As perguntas e as respostas apresentadas por Lacroix, no restante das páginas do livreto, discorrem sobre o estudo dos astros, da astronomia e, quase sempre, sugerem a conferência daquilo que está escrito com o que pode ser observado nos céus. Lacroix apresenta alguns questionamentos inerentes à geografia, como: "O que é mediana?", "O que se entende pelos quatro pontos cardeais?", "Qual é a forma da Terra?". Todas essas perguntas e respostas parecem conduzir o leitor a uma familiarização com um contexto necessário para a compreensão do que se deseja na parte final do livreto: "Descrição da Esfera Armilar" (também apresentada em forma de perguntas e respostas). É neste momento que o autor se dedica a descrever os elementos da esfera, a sua funcionalidade e a forma de manuseá-la (não a esfera do modo como suspeitávamos no início, no primeiro golpe de olhar à capa do livreto). E sobre a esfera armilar, Lacroix coloca:

Q. Por qual meio representaram-se, em menor escala, os fenômenos expostos acima?
R. Construiu-se para isso uma máquina chamada esfera armilar, da palavra armila,
que significa anel ou círculo, e formada de círculos dispostos como o são aqueles que
parecem descrever os astros, ou sobre os quais eles passam sucessivamente. No
centro, encontra-se um pequeno globo que representa a Terra, e que é atravessado
pelo eixo em torno do qual se move todo o resto da máquina. As extremidades desse
eixo chamam-se polos [ênfases no original]. (Lacroix, 1872, traduzido por Rodrigues,
2014, p. 279).

Apesar de o título anunciar uma "descrição", o autor faz mais que isso: ele apresenta várias considerações importantes para entendermos como a esfera armilar funciona, de que forma podemos manuseá-la e, a partir dessas colocações, compreender noções de astronomia.

O livreto denuncia uma preocupação de Lacroix com o ensino, e não nos causa estranheza que publicasse algo relacionado a esse assunto, pois sua obra Introduction a la Géographie Mathématique et Critique et a la Géographie Physique (1811) já abordava questões de geografia física e matemática. Como Lacroix era professor e muito envolvido com questões relacionadas às escolas e ao ensino, pode ter percebido uma fragilidade nos modos de se ensinar às crianças, mais especificamente, o movimento dos astros e, portanto, a astronomia, utilizando a esfera armilar, o que poderia disparar um aprendizado confuso e sem sentido para os estudantes. O texto do livreto pode ser considerado uma tentativa de alertar os docentes para essa fragilidade.

\section{Alguns apontamentos sobre leituras e interpretações de textos por meio da HP}

Os dois exercícios analíticos aos quais nos propusemos por meio da HP, lançando possíveis interpretações para Lacroix, nos permitem dizer sobre o referencial e relatar como Zetetiké, Campinas, SP, v.27, 2019, p.1-15 - e019015

ISSN 2176-1744 
DOI: http://dx.doi.org/10.20396/zet.v27i0.8654109

esse referencial funcionou, quando mobilizado para analisar duas obras de um autor francês (não didáticas), disparando contribuições, sobretudo, para nossos estudos em História da Educação Matemática.

Um livro tomado como forma simbólica ignora o seu fim imposto pelo autor. O hermeneuta obriga o livro a continuar, obriga a forma simbólica a continuar, e isso também contribui para que novos exames hermenêuticos sejam disparados e novos fins sejam subvertidos, já que, para nós, uma análise hermenêutica é, ela própria, uma forma simbólica. A HP, ao continuar o livro, continua o texto, seja quando toma um texto contemporâneo, seja quando toma textos escritos e publicados em outros séculos.

No caso dessas duas obras analisadas de Lacroix, em que há um significativo distanciamento espaçotemporal, a HP dá a possibilidade de o hermeneuta trazer a obra de volta à cena, com olhos contemporâneos respeitosos do tempo passado que lhe foi possível acessar e dizer sobre, para fins de interpretação. Podemos dizer, ainda, que a HP, em exercício conduzido pelo hermeneuta, permite que a obra e o autor (re)nasçam em interpretação depois de passados séculos, décadas. Portanto, analisar textos escritos pelas lentes deste referencial é uma escolha e um caminho que pode levar o hermeneuta muito mais além do que as páginas do texto apresentam num primeiro olhar, numa primeira interpretação. É um modo, consideramos, de fazer a análise extrapolar a obra, extrapolar as páginas, extrapolar um tempo e uma autoria. É um modo, portanto, de fazer o texto continuar, de sugerir novas hermenêuticas, novas leituras e o registro de (re)interpretações.

Nesses nossos exercícios hermenêuticos a HP permitiu que conhecêssemos um pouco sobre Lacroix, que conhecêssemos um pouco de sua obra e que continuássemos Lacroix. Pudemos, então, continuar o Ensaios... e continuar o livreto, ao mesmo tempo que líamos, interpretávamos e registrávamos. São dois livros que renasceram da intenção de interpretar, da intenção e da necessidade primeira de traduzir. Duas obras não muito conhecidas deste autor (se compararmos ao grande alcance que têm seus livros didáticos de matemática) que ganharam notoriedade e nos deram a possibilidade de conhecer e entender um pouco mais sobre um autor, um professor de matemática que anseia tratar de aspectos ligados ao ensino e suas intenções/reflexões naqueles contextos para além de conteúdos específicos.

O referencial indica a necessidade de idas e vindas. Ele impõe um movimento - como qualquer projeto hermenêutico exigiria - sempre inacabado, que insistentemente se (re)inicia, busca sentidos, atribui significados e permite que o hermeneuta aprofunde cada vez mais o contato com aquele livro que sua leitura cria. É assim que exames hermenêuticos conduzidos pela HP disparam possibilidades de análise que nunca se esgotam, assim como nunca se definem as possibilidades de a forma simbólica ser e estar no mundo. O hermeneuta em exercício de análise se modifica, evolui, e nada está ou será igual ao que era antes de um determinado olhar para uma forma simbólica; uma leitura sempre altera a perspectiva do hermeneuta quanto ao texto, quanto ao mundo. Esse hermeneuta, que se fez pesquisador no movimento de pesquisar, torna-se leitor, lendo o texto que permite a ele ler-se a si próprio, lendo o que lia. A aproximação congenial com um autor é, sabemos, impossível, mas o esforço para essa aproximação impossível é o que gera significados plausíveis sobre ele 
DOI: http://dx.doi.org/10.20396/zet.v27i0.8654109

próprio, autor, e sua obra. Com a HP é possível efetivar um exercício imaginativo que nos aproxima de uma época, das concepções então vigentes, das organizações sociais, culturais, políticas e econômicas de um determinado tempo-espaço que não necessariamente é o nosso.

As possibilidades de pesquisas apontadas para a análise sócio-histórica e para a análise formal ou discursiva podem, em algum momento, levar à errônea interpretação deste referencial como um conjunto de etapas a serem cumpridas. Entendemos que o que nos mostra e sugere Thompson são possibilidades, são tentativas de mobilização por ele consideradas; não se configuram, no entanto, como um conjunto de métodos engessados e obrigatórios. Pelo contrário, Thompson nos permite entender e, mais que Thompson, as nossas mobilizações nos permitem entender que a HP é um referencial metodológico aberto, que sugere alguns possíveis modos de analisar a forma simbólica, considerando texto e contexto, mas que, em construção e em constante discussão, nos permite novas tentativas, novas possibilidades e novas sugestões.

A HP, quando mobilizada para analisar textos escritos, tem também caminhos delineados pelo próprio texto, que consegue anunciar ao hermeneuta que tipo (ou tipos) de análise pode(m) ser disparada(s), naquele momento, com os recursos que lhe são acessíveis. Se tomarmos os tipos de análise sugeridos para a análise formal, por exemplo, cada uma dessas análises poderia resultar num estudo diferente da forma simbólica desenvolvida por pesquisadores de campos distintos.

As (não)escolhas do hermeneuta apresentam mobilizações que nos levam, também, a percepções de limitações, de possibilidades, de imposições (que podem ser dadas, por exemplo, pelo espaço temporal que separa o hermeneuta do contexto de produção e circulação da forma simbólica ou pelo afastamento da língua materna em que os originais estão escritos, o que é o caso das duas obras aqui analisadas). Há um intenso negociar, entre tantos possíveis, do hermeneuta com a forma simbólica, parametrizado pelo referencial. Um negociar que pode levar a parcerias com outros referenciais, como no caso da análise do Ensaios..., em que chamar à cena o auxílio de Genette (2009) e seus paratextos editoriais nos pareceu bastante recorrente e certeiro. Este é um ponto forte no movimento da HP: um referencial que possibilita várias e diferentes conexões. Não queremos afirmar com isso que a HP tudo aceita. Consideramos que, dentro dos parâmetros inicialmente sugeridos por Thompson e em movimento, sugeridos pelas pesquisas, há uma flexibilidade ao trabalhar com essa metodologia, o que permite novos diálogos metodológicos e passeios por outras searas.

Desse modo, analisar os textos escritos de Lacroix por meio da HP nos pareceu bastante interessante e funcional para o tipo de análise que intencionávamos disparar. Consideramos que nos foram possíveis análises menos descritivas (o que poderia nos levar a repetições daquilo que o próprio material apresenta, tornando-se pouco significativas em termos de interpretação, e esse não era o nosso objetivo), análises que apresentam (ou, ao menos, são tentativas de apresentar) olhares atentos para os contextos de elaboração e de publicação do material em meio a cenários sociais e políticos, às vezes conturbados e que exigem adequações nem sempre aceitas pelo autor; às vezes impostas pelo cenário e/ou pelas 
DOI: http://dx.doi.org/10.20396/zet.v27i0.8654109

editoras; ou, ainda, que revelam e refletem engajamentos culturais, sociais e políticos do próprio autor. Segundo entendemos, analisar um texto vai além de simplesmente descrevê-lo, compará-lo, falar sobre os aspectos que o compõem, biografar seu autor. Exercitando esse referencial, então, pudemos traçar essas interpretações que não dissociam texto e contexto, cuidando de compreender um possível significado e intenção daquela obra, naquele momento em que se inseriu como produção no mundo.

Esses exercícios hermenêuticos nos exigiram relatórios escritos. Um dos grandes debates em torno da HP é sobre a dificuldade que o hermeneuta possui para registrar o seu movimento de pesquisa. Isso se dá por justamente ser um movimento (quase sempre) muito dinâmico, que perde essa identidade quando precisa se render a uma linearidade da escrita. Linearmente elaboramos o registro do que foi, para nós, uma experiência vivida durante um longo período de esforços frente aos livros, às formas simbólicas. Essa experiência, no entanto, pode se dar de diferentes modos. O receio da escolha de um ou outro modo de registro é porque há um desejo de comunicar a realidade vivida pelo hermeneuta quando este transita entre a análise sócio-histórica, a análise formal e (re)interpreta a forma simbólica. Somos quase sempre traídos pela escrita, que não permite registrar a "caoticidade" enfrentada pelo hermeneuta, que o faz se perder em meio ao processo de análise (alternando-se entre texto, contexto e interpretações). Aos poucos o pesquisador dá conta de organizar esse movimento em forma de registro escrito e apresenta uma hermenêutica que parece, quase sempre, serena. E o caos presente durante o exercício hermenêutico é praticamente inexistente aos olhos do leitor.

Há de se cuidar, ainda, do que ficará registrado em movimento de análise e de interpretação e o que ficará apenas aos olhos e nos arquivos do hermeneuta, como aporte necessário para a elaboração das considerações, das informações descritivas ou minuciosas demais para compor o que será registrado como uma hermenêutica da forma simbólica. Esse cuidado é importante para não recairmos naquilo que pensamos que a HP tenta amenizar: as análises descritivas e cansativas, que pouco agregam em termos de compreensão do material de que se dispôs cuidar em análise.

É importante ressaltarmos que a HP se propõe (do modo como a entendemos a partir das disposições teóricas que nos foram acessíveis) como um dos modos possíveis de se fazer hermenêutica. Exercitar essa hermenêutica não implica negligenciar outras. O incômodo constante com o adjetivo "profundidade", que acompanha a nomenclatura dada por Thompson a este referencial teórico metodológico, não apresenta e nem intenciona, entendemos, comparação com outros modos de análise de textos. Referenciamos Thompson, quase sempre, mas acreditamos que cada exercício de análise disparado pela HP avança a proposta colocada por ele, amplia Thompson e amplia a HP.

O estudo de livros antigos nos conduz ao conhecimento de outros tempos e de outros espaços (escolares e não escolares), nos leva a compreender e suspeitar, nos permite circular entre presente e passado e ler o mundo segundo outras óticas. No nosso caso, a análise hermenêutica dessas duas obras de Lacroix nos permitiu explorar (criar plausivelmente) uma história de cada uma delas; possibilitou conhecermos interesses, processos, intenções, 
DOI: http://dx.doi.org/10.20396/zet.v27i0.8654109

subversões e aceitamentos, avanços e retrocessos, muitos deles ainda atuais; possibilitou analisar nosso tempo e aquele tempo, nossa escola e aquela escola, nossas práticas e aquelas práticas.

A HP, portanto, aposta nas inúmeras possibilidades de compreender as tramas entre materialidade e ideologia quando entrelaçamos texto e contexto. É mais que um simples registro descritivo do que a obra é, foi ou pode ser: é um conjunto de atribuições de significado que se funda na mobilização de uma pluralidade de olhares e de movimentos, sem esconder as tramas que culminam na configuração do "arremate final", chamado de interpretação/reinterpretação. Toda informação leva a outra informação, toda descoberta induz novas descobertas, novos detalhes, outras "amarrações". Sem o entrelaçamento entre texto e contexto, uma hermenêutica - qualquer que seja ela - é impensável. Sem entrelaçamento entre texto e contexto, há descrições.

No trabalho com a HP, nosso desejo é também mostrar as linhas que nos permitem realizar costuras e que nos conduzem aos chuleados mais adequados (de acordo com as lentes que nos são possíveis). São, justamente, os nós e as laçadas o que apresentamos, ao descrever os momentos e os movimentos analíticos (sobretudo durante a análise sócio-histórica e a análise formal), as linhas e as cores que nos conduzem para a tessitura deste arremate final (a apresentação de uma interpretação/reinterpretação que se constituiu e se reconstituiu no decorrer das nossas análises).

Compartilhar esse modo de produção não só permite como motiva o leitor a lançar-se num esforço de, ele próprio, buscar outros fios e tentar outras dentre as tantas laçadas possíveis, já que um processo hermenêutico é, sempre, um movimento inacabado, impossível de ser, de modo definitivo, encerrado. E seria, então, uma ousadia chamar essa interpretação/reinterpretação de arremate final. Para nós, na HP, o arremate consiste na obra da mão e do trabalho daquele que se lança a interpretar uma forma simbólica por meio de diferentes análises - o hermeneuta. Portanto, há mais do que um arremate final: há este arremate (de acordo com as condições com as quais nos defrontamos durante a pesquisa), dentre as várias possibilidades de arremate, e sempre haverá outros hermeneutas e outros arremates possíveis.

Outra contribuição importante desses nossos dois exames hermenêuticos de textos não didáticos de Lacroix é que eles nos lançam a possíveis (re)interpretações das obras didáticas deste autor. Aproximamo-nos de Lacroix, estranhamos menos sua mentalidade de autor no contexto em que estão fixas a produção de sua obra e as intenções para a produção de parte delas. É possível olhar para as obras deste autor, agora, e entendê-las como parte de um contexto histórico específico, influenciadas por esse contexto e influenciando-o. Analisar o Ensaios..., por exemplo, nos coloca em contato com uma análise que o próprio autor faz de parte dos livros didáticos nos quais assina autoria. Uma autoanálise bastante interessante que se escondia nas páginas desconhecidas de um texto. Conhecer Lacroix na análise do Ensaios... nos forneceu parâmetros para que a análise do livreto fosse menos estranha aos nossos olhos, tanto em termos de conteúdo apresentado no material como em termos de exercício metodológico. No segundo exame hermenêutico já nos era conhecido o autor, o seu 
DOI: http://dx.doi.org/10.20396/zet.v27i0.8654109

posicionamento frente ao contexto educacional daquela época, e algumas interpretações foram disparadas a partir do que a primeira análise nos levou a considerar. Temos, agora, um autor irremediavelmente entranhado em nós. É este, portanto, um ponto importante para nós, que desejamos continuar olhando para a obra deste autor e interpretando-a.

\section{Referências}

Andrade, M. M. (2012). Ensaios sobre o Ensino em Geral e o de Matemática em Particular, de Lacroix: análise de uma forma simbólica à luz do Referencial Metodológico da Hermenêutica de Profundidade. Tese de Doutorado em Educação Matemática. Rio Claro, Universidade Estadual Paulista (UNESP). Retirado em 16 de agosto de 2018 de: http://hdl.handle.net/11449/102111.

Andrade, M. M., \& Oliveira, F. D. (2014). Referencial metodológico da hermenêutica de profundidade na educação matemática: reflexões teóricas. In A. V. M. Garnica, \& M. E. M. Salandim. (Eds.), Livros, leis, leituras e leitores: exercícios de interpretação para a História da Educação Matemática (pp. 17-42). Curitiba: Appris.

Garnica, A. V. M., \& Salandim, M. E. M. (2014). Livros, leis, leituras e leitores: exercícios de interpretação para a História da Educação Matemática. Curitiba: Appris.

Genette, G. (2009). Paratextos editoriais. Cotia: Ateliê Editorial.

Lacroix, S. F. (1838). Essai sur l'enseignement en général, et sur celui des mathématiques en particulier (4a ed.). Paris: Bachelier, Impremeur-Libraire.

Lacroix, S. F. (2013). Ensaios sobre o ensino em geral e o de Matemática em particular. (Karina Rodrigues, Trad., Antônio Vicente M. Garnica e Maria Laura Magalhães Gomes, Notas). São Paulo: Editora Unesp.

Lacroix, S. F. (2014). Introdução ao Conhecimento da Esfera. Paris. In A. V. M. Garnica, \& M. E. M. Salandim. (Eds.), Livros, leis, leituras e leitores: exercícios de interpretação para a História da Educação Matemática (pp. 275-294). Curitiba: Appris.

Oliveira, F. D. (2008). Análise de textos didáticos: três estudos. Mestrado em Educação Matemática. Rio Claro: Universidade Estadual Paulista (UNESP). Retirado em 10 de novembro, 2018, de: http://hdl.handle.net/11449/91113.

Oliveira, F. D. (2014). Hermenêutica de profundidade: um contexto. Anais do Encontro Nacional de Pesquisa em História da Educação Matemática (pp. 98-103), Bauru/SP, 2.

Thompson, J. B. (1995). Ideologia e cultura moderna: teoria social crítica na era dos meios de comunicação de massa. Petrópolis: Vozes. 